\title{
Diagrams, Conceptual Space and Time, and Latent Geometry
}

\section{Towards the Development of Euclidean Axiomatics}

\section{Lorenzo Magnani ${ }^{1}[\mathbb{C}$}

Received: 14 October 2020 / Accepted: 3 January 2021 / Published online: 8 February 2021

(c) The Author(s) 2021

\begin{abstract}
The "origins" of (geometric) space is examined from the perspective of the so-called "conceptual space" or "semantic space". Semantic space is characterized by its fundamental "locality" that generates an "implicit" mode of geometrizing. This view is examined from within three perspectives. First, the role that various diagrammatic entities play in the everyday life and pragmatic activities of selected ethnic groups is illustrated. Secondly, it is shown how conceptual spaces are fundamentally linked to the meaning effects of particular natural languages and these are very different from the global and universal aspects of Euclidean spaces. Thirdly, it is contended that these modes of creating body and culture-based spatial frameworks and related cosmogonies and cosmologies can be described as forms of "latent geometry" that initially appear unexplainable in any rational way. Nonetheless, and thanks to the deep mathematical reflections provided by René Thom, it is illustrated how the various ways of generating space can be further analyzed as distortions of mainstream spatialization furnished by Euclidean geometry that established the dominant universality of the ideas of space (and time).
\end{abstract}

Keywords Semantic spaces - Conceptual space - Cosmogony: cosmology - Body · Latent geometry $\cdot$ Rituals $\cdot$ Origin of geometry $\cdot$ Euclidean space

\section{Introduction}

This article will address the problem of the representations of space and time in the light of a basic theoretical framework that follows the fil rouge of the interplay between the latent geometry, which is embedded in rudimentary

Lorenzo Magnani

lorenzo.magnani@unipv.it

1 Department of Humanities, Philosophy Section and Computational Philosophy Laboratory, University of Pavia, Pavia, Italy 
representations - basically generated thanks to natural language-and their full rational reconstruction, fundamentally due to the ancient Greek mathematics, and its repertoire of complicated artificial languages, enriched with the smart exploitation of rigorous diagrams. In the case of latent geometry representations, bodies, and abstract and material artifacts such as homes, commerce, moving, routes, maps, rituals, and worldviews, play a fundamental role and cosmology construction is often entrenched in those simple representations, contrarily to the case of explicit geometrical accounts, which create the first condition of possibility of the future rational cosmologies as they are due to modern science.

The examples that are illustrated come from anthropological research regarding XX century people, the traditions of Kabbalah (since XIII century) and Yantra (very remote in Tantra tradition, starting in the early centuries of common era, even if the appearance of the term "Tantra" in Indian texts dates back to 1700-1100 BC) ), ancient Greece studies and some important philosophical reflections inspired by the mathematical theory of catastrophes created by René Thom.

Taking advantage of the intellectual tradition of philosophy of science, logic, and cognitive science, which are at the basis of my profile as a researcher, this article aims at avoiding the theoretical poorness of treatments that are merely historical/ informative and at the same time the excessive "technical virtuosity" of the studies conditioned by the academic habits of analytic philosophy. I am not referring here to some historico-critical studies such as for example the important one by Torretti (1978), which certainly represents a research that cannot be classified as merely historical/informative and in which the presence of technicalities is always motivated by the context and not an abstract and scholastic exercise. Further, other examples can be found in the area of the recent renaissance of studies on Husserl's early work, in which the historical interest is accompanied by a constant theoretical and deep philosophical commitment (see for example Centrone (2017)). ${ }^{1}$

Instead, by adopting a theoretical and critical attitude that does not disregard data provided by various disciplines, I think that interesting results are achieved. The approach to the role of diagrams, conceptual space and time, and latent geometry in the light of the development of Euclidean axiomatics furnishes a privileged philosophical and cognitive tool able to generate a satisfactory description of the slow transition to the production of concepts endowed with a "universal" value. These concepts represent the first condition of possibility of the establishment of rational perspectives on cosmologies.

Historical, anthropological, and cognitive studies regarding the problem of the "origins" of geometry illustrate many interesting ways to conceive the role of geometry and space, which are basically considered in the view of the role of diagrams in variegated pragmatic activities (everyday life, home, body, commerce, moving, routes, maps, rituals, worldviews). These kinds of cognitive activities originate what

\footnotetext{
1 I myself devoted, some decades ago, a historico-critical analysis to the development of the non-Euclidean geometries (Magnani 1978).
} 
I call "conceptual space", 2 often characterized by a "locality", which in the perspective of the scientific eye can be seen as fragmentary and geometrically implicit. Conceptual space must be fundamentally linked to the centrality of its proximity and of the meaning effects of natural language: it is local, even if the related diagrams can become shared by the members of human collectives of various size, and related to multiple forms of duration and representations of time. Conceptual space is very different from Euclidean space: all these ways for generating spatial frameworks of various kinds, issued from subjects' bodies and cultures, can be considered as innumerable forms of "latent geometry", at the first sight devoid of any possibility of being explicitly and rationally exhibited. However, spatial frameworks (and the temporal schemes they originate) are not so enigmatic and non-analyzable because they can be modeled in a rational way by enhancing the resources of the mere natural languages. The main ways for generating space will turn out to be explicit in light of the Greek accomplishments in terms of symbolization, axioms, and rules of inference, where the universality of the related ideas of space and time is established.

\section{Conceptual Semantic Space and Protogeometrical Shapes}

\subsection{Semantic and Latent Space, Homes, and Bodies}

The concept of mentality is particularly appropriate when we need to study the first ways human beings adopted to create spatial frameworks, to see the distance from current common representations of space, certainly influenced by Euclidean geometry. What we immediately see is that the representations of space of people not influenced by Euclidean geometry is eminently symbolic, often close to rudimentary topological shapes, to adopt a modern mathematical term.

For example, the mentality of some traditional African ethnic groups presents an idea of space that is fundamentally conceptual, in which notions such as in/out, high/low, central/peripheral, right/left, closed/open, symmetrical/asymmetrical, are central and always linked to non spatial considerations related to the everyday life. As I just mentioned we can say that this way of "making space" reflects a topological order: in this perspective I frame that process thanks to a contemporary technical notion, but I think this is not sufficiently explanatory and surely Western-centric.

The idea of conceptual semantic space (or just of semantic space) derives from the fact that spatiality is basically generated by natural language. I can call these spaces conceptual because their meaning is created thanks to the effect generated

\footnotetext{
${ }^{2}$ My use in this article of the term "conceptual space" does not have a special technical meaning, such as for example in the studies proposed by Gärdenfors (2000), which aim at building, also thanks to the use of geometrical structures, a bridge between the symbolic and connectionist approaches derived from computer science. Hence, we are certainly dealing with a terminological convergence but the two uses of the expression actually refer to theoretical perspectives that are different, even if they have a common insight as their starting point. My "conceptual spaces" originate in the effective and practical activity of natural languages, and do not refer to special intellectual technicalities related to recent computer science, logic, and philosophy.
} 


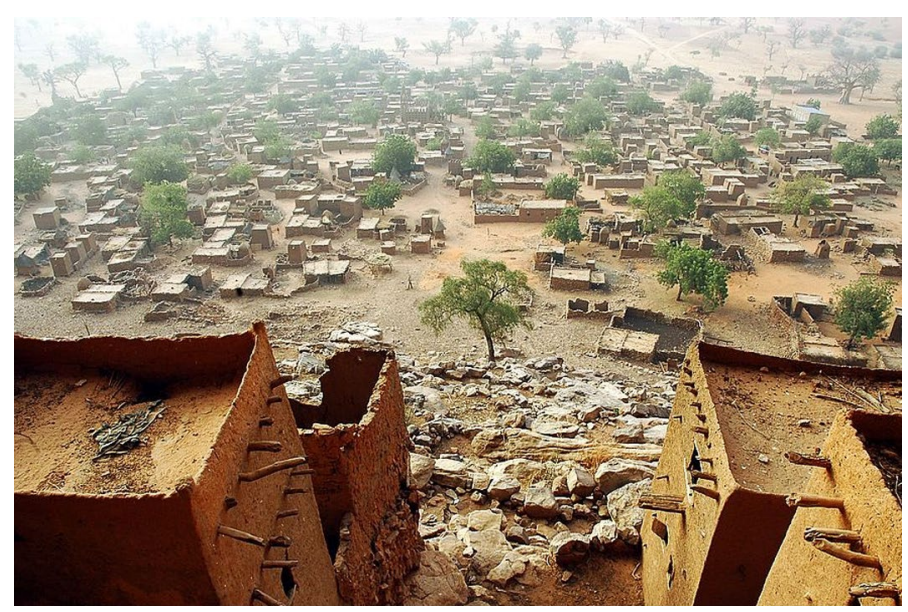

Fig. 1 Looking down on a Dogon village

by a propositional tool, and not in the framework of technical artificial language such as the one of geometry. Thanks to internal (mental) and external representation spatiality emerges as intertwined with (and linked to) actual aspects of the natural environment (for example, sky/earth, village/forest, beach/sea). Spatiality is "precipitated" in external entities (natural and artificial), props, and human-made shapes, reverberating prototypical icons (for example bodies or parts of the bodies or dwelling) endowed with cosmological, moral, religious, and social values. In the case of the Dogon-for looking down on a Dogon village see Fig. 1-which are an ethnic group indigenous to the central plateau region of Mali, in West Africa, south of the Niger bend, near the city of Bandiagara, and in Burkina Faso, we find the semantic space that is described in the following passage:

The big house [of each lineage within the village] comprises the dembere or "room of the belly", that is to say, the central room, around which are placed a kitchen (obolom), three store-rooms (kana), a stable for goats (ende) and the denna or big room, flanked by the entrance (day) and another stable (bel de). On either side of the entrance and the corners of one of the rooms are four conical towers surmounted by domes (arsobo). The plan of the building is said to represent, on the one hand Nommo [the son of God] in his human form, the towers being his limbs; on the other hand, the kitchen and the stable are said to be the heavenly placenta and its earthly counterpart, together representing the head and the legs of a man lying on his right side [and copulating], whose other limbs also have their architectural counterparts: the kitchen represents the head, whose eyes are the stones of the hearth; the trunk is symbolized by the dembere, the belly by the other room, the arms by the two irregular lines of store-rooms, the breasts by two jars of water placed at the entrance to the central room. Finally, the sex organ is the entry which leads by a narrow passage to the work-room, where the jars of water and the grinding-stones are kept. 
On these, young fresh ears of new corn are crushed, yielding liquid which is associated with the male seminal fluid and is carried to the left-hand end of the entry and poured out on the shrine of the ancestors [Griaule and Dieterlen (1954) in Hallpike (1979), pp. 289-290].

The main relation is between space and human body and between this last one and ritual locations. ${ }^{3}$ The Dogon also build oval villages that mime a cosmic ovum, which develops from growing seminal cells and that is full of anthropological shapes: it represents a person in the north facing the south, the forge is the head, various altars are the feet, the huts used by the women when menstruated are the hands, the habitations of the families are the thorax, a hollow stone located on a cone-shaped altar outlines the female and male genitals respectively.

In the Dogon case and in other cases that are very similar we see active a "conceptual" effect that resorts to a reference not only to the human body but to a complicate cluster of ritual, mythical, cosmogonic and cosmological aspects, all expressed and rendered intelligible thanks to natural propositional language, and not derived, as in the case of the modern idea of space, from the Euclidean geometry, based on an artificial mathematical language. It is what the western culture called the correspondence between microcosm and macrocosm, a worldview active until the Renaissance, also present in esoteric traditions such as cabala (cf. below Sect. 3) and also still active in the restricted collectives devoted to occultist or magic rituals and performances.

\subsection{Spatiality, Artefactual Entities, Microcosm/Macrocosm, and Cosmogony}

Another example of cognitive delegation of a framework for spatiality to external artefactual entities is present in Malaysian people's cosmology, in which the world was depicted as a quadrilateral. When they founded a good location, a rectangle of sticks was built in the center of the area and a ritual was celebrated to bless the result by addressing a prayer to the lord of the site:

If the omens are good, the four corners of the main building are pegged out with dead sticks and the area cleared. Then the ceremony for erecting the central house-post is begun. The shed that forms the Malay theater is square. The pawang [magician] defines the space needed for the performance by moving from within the enclosure "four paces in each direction of the four corners of the universe" and asks the spirits within that area not to be disturbed [Endicott (1970) in Hallpike (1979), p. 295].

Microcosm-macrocosm correspondence is still at play, embedded in the intertwining between spatial, cosmological, and ritual representations, and also shows (of course if we adopt the modern perspective of the geometrical lexicon) the

\footnotetext{
3 On the different conceptual role of rituals in the cognitive, psychoanalytical, and anthropological perspective of the concept of manipulative abduction and in the framework of the theories of extended, disembodied, and distributed mind in the creation of new concepts and practices cf. (Magnani 2018).
} 


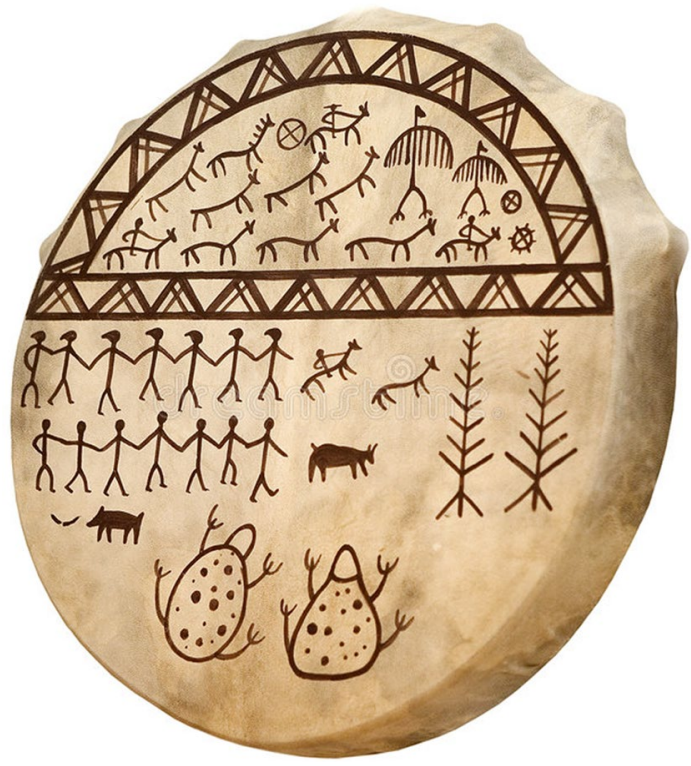

Fig. 2 The painting of a drum as the symbol of the shaman

intrinsic use of a Euclidean quadrilateral geometric shape: indeed, in this case the shape is called "geometrical" because of our modern interpretation in terms of Euclidean geometry. This leads to hypothesize in those representations a hidden activity of something "geometrical", still confused and informal. Of course the mentality presents various cases of intrinsic "geometricity": in the following paragraphs I will describe another more advanced use of a protogeometrical idea, not merely referred to the geometrical Euclidean forms, but to the implicit partial building of a Euclidean reference system, which indeed portrays something beyond the exploitation of merely protogeometrical more or less regular forms.

It is the form of both human body and concentric circles which refers to the microcosm-macrocosm relation: man is a knot of cosmic correlations. Figure 2 indicates the painting of a drum as a symbolization of a special kind of human being: the shaman. We see at the top the celestial portion and two big frogs at the bottom, which symbolizes the earthly part. The Canis Maior can be individuated in the frog laid over the antique astrolabe and the Hydra in the serpents on the right of the frog (Zolla 1985).

It is clear that the use of the body to represent spatiality in the case of houses and villages is also related to various type of orientation, which in turn are suitably connected with conceptualizations that express archetypical myths and the internal parts endowed with ceremonial, ritual, and sacred values and worldviews. The Kedang of western Indonesia, a people moved by the Dutch administration close to the beach (they were instead located near the Udijo Lewun volcano), preserved a volitional stone called koda in the oldest spatial part of their village. Indeed Koda indicated for Kedang the summit of the mountain, which 
they believed to be the generator of the human race (whose ancestors lived on): "Koda stands therefore for the connection which each village maintains with the original site of habitation, and consequently with the descendants from that side in other villages" (Hallpike 1979, p. 291).

\subsection{Protomathematical Frameworks}

Compared to the examples above, much more interesting, in the light of its closeness to the spirit of Euclidean geometry, is the "mental" generation of a true protosystem of coordinates. Here and in the following of this article, the reference to the coordinates is further related to what in modern times have been called Cartesian coordinate system. This protosystem is promoted by the practical need of creating itineraries and "mental maps" for navigation, as a person's point of view perception of his area of interaction, indeed mental maps refer to both social and geografical aspects.

The Australian aborigines exemplify this case of first elaboration of itineraries. The mental map exploited in the case of aborigines' travels is very different with respect to our modern geographic account. The aborigines adopted a reference system which consisted in a continuous updating of a local spatial map rendered available to the individual, thanks to the subsequent exploitation of signs and landmarks such as the winds, aspects of the soil, position of sun, etc. As it is well-known a landmark is a recognizable natural or artificial aspect used for continuing to walk to a certain destination, navigation, etc., an element that stands apart from its close environment and is frequently noticeable from significant distances. We have to note that there is no reference to an idea of space as global and unique. Hallpike himself usefully comments:

Lewis's informants said explicitly that they kept the directions "in their heads" rather than relying on the sun, and as we can see from the map, which is a very distorted representation of the track followed, they could orient themselves on the ground very accurately although unable to draw their track: this diagram is geographically distorted in respect to directions, angles and distances, but the "map inside Wintinna's heads" was clearly attuned to the actual conditions "on the ground". For, after 3 days and $75 \mathrm{~km}$ of angled courses off tracks of any sort (but with occasional landmarks) he directed the Land Rover straight to the water-hole across the plain (Hallpike 1979, pp. 304-306).

The itinerary is individuated thanks to details that do not refer to a global vision. Only local intrinsic specificities are taken into account to iteratively solve the problem of connecting two points in space. I am saying "in space" because I am adopting the modern perspective of the universal geometrical coordinates, which depicts a global space, but in our case the concrete meaning for the Wintinna of the word "space" resorts to a mere set of local data appropriately exploited to get a route and its features.

Another typical character of semantic spatialization is represented by the metrical distortion of some Eskimo maps where, contrarily to our modern geographic maps, certain areas have special meaning" and so they are exaggeratedly big (for example 


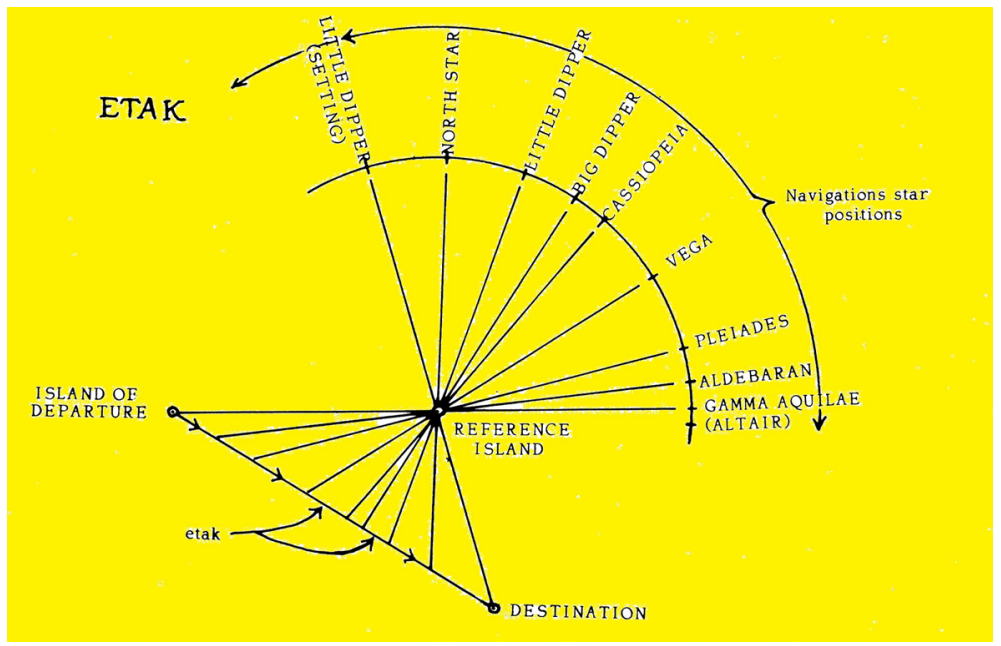

Fig. 3 The etak navigation system. (From Gladwin, 1970, p. 185, copyright (C1970 by the President and Fellows of Harvard College, Harvard University Press, Cambridge, MA, reprinted by permission)

hunting fruitful sites). Usefulness is the main reason that governs the spatial mental image (and the eventually externalized rudimentary depicted map) of an island in which a part is very huge. No more soil, winds and sun orient the spatialization, as in the previous case, but very pragmatic elements related to food and fishing.

A special case is presented by the way the natives of the Puluwat atoll of the Caroline Islands (now in the Republic of Micronesia) adopt in the case of navigation. The system is called by the anthropologists etak and is related to the "implicit" exploitation of portions of the Euclidean straight line and in the transformation of natural entities, the stars, in what I called called "cognitive mediators". This expression, extendedly illustrated by Magnani (2001a), is derived from Hutchins, who introduced the expression "mediating structure", which regards external tools and props that can be constructed to cognitively enhance the activity of navigating. Written texts are trivial examples of a cognitive "mediating structure" with clear cognitive purposes, so mathematical symbols, simulations, and diagrams, which often become "epistemic mediators", because related to the production of scientific results (Hutchins 1995). function as an enormous new source of information and knowledge. The etak system consists in the ability to connect two points, the use of angles and generally the implicit exploitation of a mobile system of coordinates rooted in the paths of the stars, thanks to the idea of distance as related to velocity and time that passes (Fig. 3):

The star bearings of the reference island from both the starting and ending points of the trip are known, since on another occasion the reference island may itself become a destination. In between there are other navigation star positions under which the reference island will pass as it "moves" backwards. Its passage under each of these stars marks the end of one etak and the begin- 
ning of another. Thus the number of star positions which lie between the bearing of the reference island as seen from the island of origin and its bearing as seen from the island of destination determine the number of etak, which can here be called segments, into which the voyage is conceptually divided. When the navigator envisions in his mind's eye that the reference island is passing under a particular star he notes that a certain number of segments have completed and a certain proportion of the voyage has therefore been accomplished (Gladwin 1970) quoted in Hallpike 1979, p. 312)).

Of course, I have to add that to find the point which corresponds to the etak island, the navigator has also to exploit a local map, which rudimentary includes the system of the various islands, and consequently also the starting point related to the star. In the etak system, the adoption of portions of a straight line is very close to some aspects of the Euclidean geometric spatial system. We have to remember that Euclidean geometry is a mathematical system credited to the Alexandrian Greek mathematician Euclid, which he portrayed in his great treatise called the Elements. Moreover, Euclid's method is the ancient model of hypothetical-deductive systems, consisting in adopting a small cluster of axioms- "postulates", in Euclid's terms-given as evident, and deducing other propositions from these, which are called "theorems".

The spatialization that underlies the etak system is less semantic-oriented with respect to the previous cases: however, it is just a kind of fraction of a whole Euclidean framework. Protoeuclidean shapes are disseminated in various ethnic collectives in the preparation of tools, religious and ritual instruments, ornaments and in what I call, in absence of other interpretations, artistic objects. Of course both metric and projective elements are lacking, and the use of protoeuclidean shapes is totally unrelated to the complete and global Euclidean system of coordinates, even of the local kind, as we have seen instead in the "fraction" of the Euclidean spatial framework of the etak methods of the Puluwat atoll people.

In summary, all the shapes and spatial structures which we have seen until now can be considered as based on local perspectives, linked to subjectivity, and not seen as interrelated among themselves in the objective generality of an axiomatic deductive system, as in the case of Euclidean of projective theorization of geometry. Also the representations of time share the same kind of "locality": the related mentalities are far from idea of an objective, universal and linear temporality. Bergson (1913) already criticized the idea of time typical of our civilization that is, he said, a "spatialized" temporality, which is in tune with the construction of a global type of geometric reference system, and unrelated to the idea of time as "duration". Once endowed with cinematic aspects, that is with velocity, this kind of temporality becomes objectified, and receptacle of every experience, such as it is in the Newtonian mechanics (Piaget 1970). Indeed, three-dimensional, measurable, quantitative, homogeneous, and universal time, even if fruit of mathematical and physical intelligibility, becomes part of our everyday intuitive representations and at the same time the support of all other qualitative (conceptual) temporal frameworks, as are subjectively and collectively transferred through language and mental models. 


\subsection{Space, Time, Duration and the Role of Cognitive Psychology}

Many ethnic groups practice temporal frameworks in which "qualitative" and "conceptual" aspects refer to multiple kinds of duration that complicate, for example, the same ideas of succession and of simultaneity, so simple in our modern western temporal judgments. Examples are expressions reported by the anthropologists such as "If we walk quicker, the sun will disappear quicker, if we walk slower, so would the sun". In these cases the time is always framed in specific situations endowed with various characters: linear (for example in the narrative regarding the history of a collective) cyclic (the seasons), reversible (tides), alternating (exchange of gifts between two persons), progressive (reaching the acme in the occasion of special celebrations, for example the feast of the pig in New Guinea), in terms of ups and downs, of continuous and unnoticeable transition, and catastrophic (Hallpike 1979). Temporal frameworks are sometimes depicted thanks to spatial local representation so that references to past times is realized thanks to spatial relationships between collectives, groups, or temporal fragments of the day in terms of living spaces of the house or of the village, etc.

On the rich empirical research in cognitive psychology three basic references regard the one inserted in the tradition inaugurated by Johnson-Laird (1993) concerning mental spatial models, the tradition of studies on spatial and diagrammatic representations (Shin et al. 2018), and the classical research by Barbara Tversky concerning the relationship between language and spatial models, memory, observation, and the role played by maps, environments, and graphs, and the role of body, has also to be cited. ${ }^{4}$ These studies have also detected many violations of the Euclidean preservation of metric properties. I have to add that the metric is a function that describes a concept of distance between any two members of the set, which are usually called points. The metric always satisfies few clear properties. The standard metric space is the 3-dimensional Euclidean space. Indeed, a "metric" is the generalization of the Euclidean metric deriving from the basic properties of the Euclidean distance: it is well-known that the Euclidean metric individuates the distance between two points as the length of the straight line segment linking them.

In this perspective violations are explained by the fact that there is not a kind of geometrical tool in eyes or brain that provides the coordinates of external entities. It is important to note that, also in these modern cases, analogously to the ones regarding the mentality of ethnic groups I have quoted above, in memory of maps and environments, there are distortions of alignment, ${ }^{5}$ which in general are generated by the influence of conceptual aspects. The use of some landmarks as reference entities can distort distance estimates and egocentric perspectives magnify the immediate

\footnotetext{
${ }^{4}$ Cf. (Tversky 1994, 1995, 2001; Tversky et al. 2006). The problem of body interaction with the world and of kinesthetic aspects is analyzed, from the philosophical perspective of Husserl, in Magnani (2001b, chapter seven).

${ }^{5}$ I this article I repeatedly made reference to some kinds of spaces as distortions of mainstream spatialization. I have to add that these spaces, if seen in the perspective of a non-standard and non-propositional logic, for example the one advanced by Brenner and Igamberdiev (2021), which looks at modeling real processes, can be considered logically valid alternatives.
} 
environment relative to distant environment (Tversky 1981, p. 269). I have also to finally note that in the case of state and city maps certain distortions are allowed to favor relevant "semantic" information, because they are useful. Itineraries are represented in the motoring maps to furnish more useful than more precise maps to favor some people's aims and needs in reaching destinations.

\section{Spatializing Through Symbols: Cosmogony}

To study the role of "symbols" in spatialization it is useful to refer the tradition of the cabala and of tantric religion. First of all we have to clarify that here the word symbol is intended in its more extended anthropological sense, also including the psychoanalytical extension-proposed by Jung —of its meaning with respect to the Peircean/semiotic tradition. The activity of delegation to external objects of cognitive values through the construction of artifacts is certainly semiotic in itself (and of course a diversion of libido/psychic energy, in Junghian terms), but the result is the emergence of new very multiple intrinsic meanings expressed by what Jung calls a "symbol" (Jung 1972)—which consequently refers to various aspects of conscious and unconscious individual and social life of collectives.

Hence, in this perspective the meaning expressed by a "symbol" is inexhaustible: two cases of spatial shapes extremely expressive come from the tradition of the Kabbalah and of tantric religion, spatial shapes which produce in themselves a huge variation of dense meanings. Figure 4 reproduces an image that comes from the Sefirot's Kabbalistic precepts (and represents the diagram of the 10 Sefirot). In the esoteric tradition of the Kabbalah (a mystic and theosophical system based on Jewish mysticism active at least since XIII century), the reference to the geometric diagrams of the 10 Sefirot indicates a kind of cosmogonic knowledge (Fig. 4).

The Sefer Yezirah, may be the oldest existing text of systematic Kabbalistic thought, teaches the following worldview: god created the world by means of 32 secret roots of wisdom which are expresses as the 10 Sefirot and the 22 elementary letters of the alphabet (Scholem 1982).

Hence, the Sefirot (singular: Sefirah) show an interesting and rich dynamics, which is endowed with religious, theosophical and cosmogonic aspects. With respect to the local ways of spatializing that I have illustrated in the previous section, we are facing now a richer representation, crystallized in an external entity, which plays the role of a mediator able to favor mental thoughtful lucubrations. As I have reported in a previous book The Sefirot

[...] aid concentration in prayer, and represents the stages of god's hidden life, as well as recounting the story of the emanation of god's world (in connection with the Gnostic and Neoplatonic ideas). It constitutes God's attributes, it is the root and the explanation of every change in the world, a theosophy of the revelation of being, the archetype of every creation, anthropomorphic symbolism of primordial man (each Sefirah represents a part of the body), cosmological image which refers to the medieval universe constituted of ten spheres, corresponding to various groups of numbers (the first Sefirah is null, 

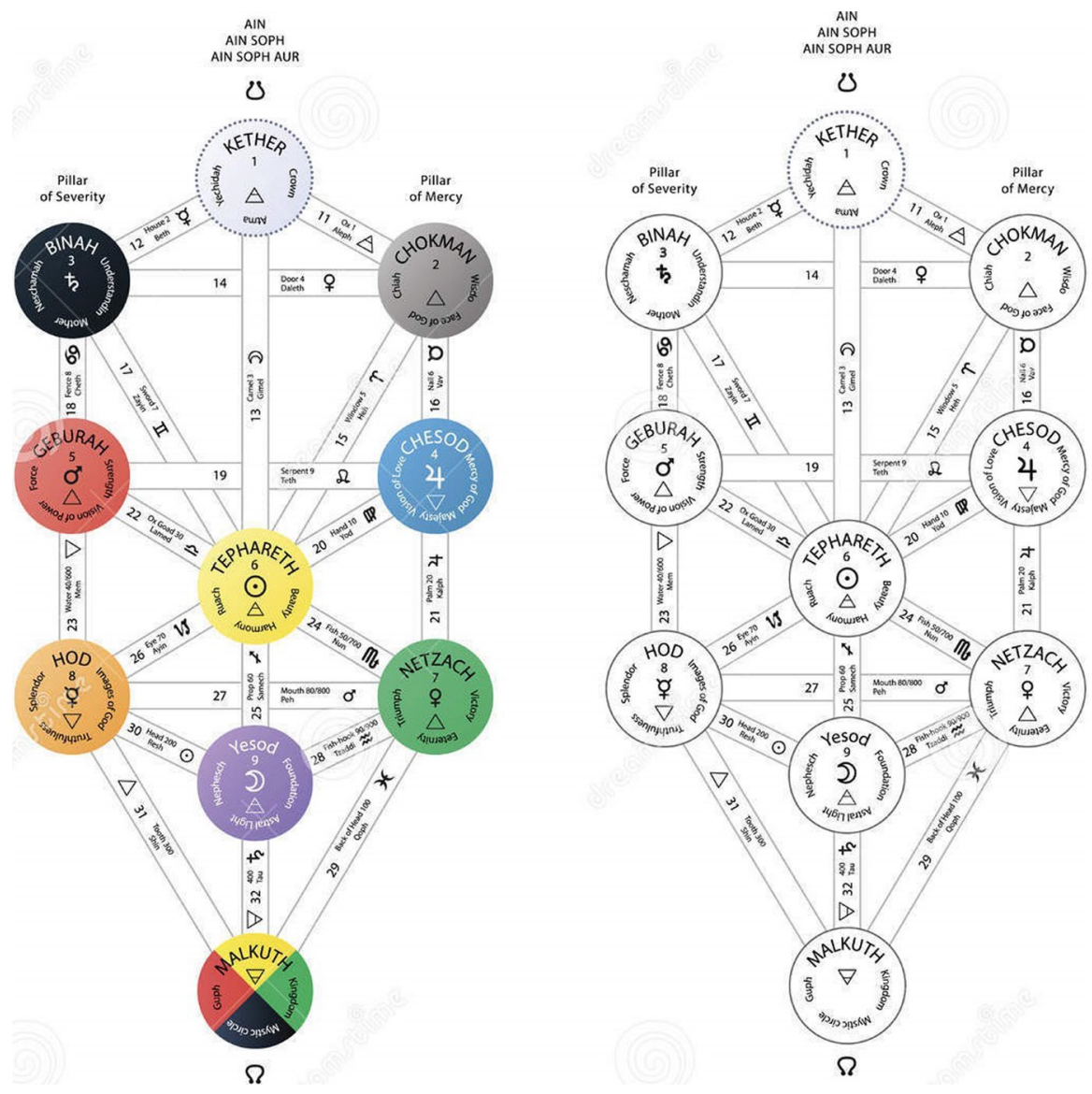

Fig. 4 Detailed Sefirot tree of life, cabala scheme on white

zero, the second is the primordial point, one, etc.) The list is not yet complete, the Sefirot are also images portraying the evolution of will power into thought, and from thought to intellect, manifestation of god's will, representation of the celestial Bear and biblical heroes, mythical symbolism (for example, the last Sefirah indicates the female principle), index of the location containing all inferior, cyclic possible and precedent worlds (in this last case, quite similar to typical motifs of Indian philosophy: the Kabbalah contains the complete doctrine of Shemitott, a cosmic cycle of 6000 years), representation of the origins of evil (for example, as emerging from previous worlds) (Magnani 2001b, pp. 16-17).

From the mystic point of view, the cosmic process is considered to be basically linguistic, rooted in an infinite association of the letters, sometimes also studied thanks to numbers. The tree-like symbolism is also rendered in some upside-down trees which reflect the diagram of the Sefirot with some symmetry. Leaves are at the level of the roots and 


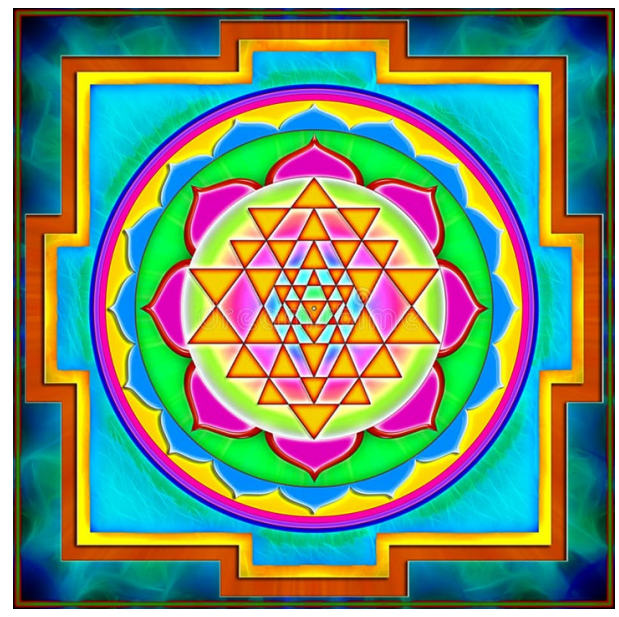

Fig. 5 Shri-Yantra

the roots of the branches. The superior portion, that is the roots that take the place of the branches, is enlightened and represents the life illuminated by the sun above, which arrives from the sky and pervades into the earth (this image is also widespread in Hindu symbolism and we do not have to forget the well-known representation of Adam and Eve's tree of knowledge of good and evil (Chevalier 1969. vol. I, p. 28)).

Another interesting form related to a spatial crystallization of a plenty of meanings in an external entity is the yantra geometric diagram. Figure 5 represents the Shri-Yantra of the religious tradition of Hindu Tantrism starting in the early centuries of common era (even if the appearance of the term "Tantra" in Indian texts dates back to 1700-1100 BC). As a support to meditation it renders visual the paradox of eternity and time thanks to a diagrammatic geometric image. The suffix "tra" in Sanskrit is adopted to indicate instruments and tools. As a kind of pre-industrial and pre-technical machine of worship, in Hindu religious tradition yantra in general refers to idols, pictures and diagrams (Zimmer 1946, p. 141): the yantra is in general an instrument to do yam, which indicates subjugation, regulation, control, and moderation. The yantra refers to Gods, also as a tool for approaching divinities and dislocating them in our hearth, and so it reproduces the process of the incremental evolution of a whole worldview when the ego of the believer mirrors himself thanks to the various elements included, that is the divinity in all its phases of transformation. The yantra, like the Sefirot, is essentially a dynamic instrument.

It is clear that also the Shri-Yantra illustrates a cosmogonic and cosmologic story: it is an illustration of the several levels and aspects of the Absolute "in the evolution and involution of the world" (Zimmer 1946, p. 142). The external square structure refers to a temple with four doors, it is the kingdom of the divinities and at the same time the center of the believer's heart.

In the variant of the cosmic flower, typical of Tibet, the central figure of god is the eternal Adi-Buddha and eight manifestations of its essence derive from it, each in special colors and attributes, giving rise to nine divine figures, such as the triangles 
of the Shri-Yantra of Fig. 5. The nine triangles infiltrate in each other, five towards the top and four towards the bottom, so representing the male and female icons, substance of god and his consort. The Absolute itself, the Really Real, is not depicted because no representation is possible, being beyond form and space. ${ }^{6}$

Tversky teaches us that written language is an event posterior to geometrical shapes, which "[...] whether drawn in sand or on paper, whether inscribed in stone from wood, appeared in ancient cultures all over the world" (Tversky 1995, p. 31). We have seen that geometrical shapes are basically full of the concepts and meanings they are able to mediate, exploiting spatial dispositions of diagrams, symbols, or icons (and thanks to the combinations of them through maps, trees, and through what we now call Venn or Euler diagrams). We can remember that in the case of Sumerian cuneiform (Schmandt-Besserat 1984) the development of schematization towards geometrical shapes of icons was a fundamental step to construct a wonderful more fruitful tool in terms of its representational power: "Cuneiform was inscribed using a stylus in wet clay, whereas hieroglyphs were drawn on papyrus (or inscribed in stone). Although many cuneiform patterns and glyphs started iconic, they became schematized, and in different ways" (Tversky 1995, p. 35). Also the first mathematical symbols did not reproduce the sounds of the names of the numerals or operators but were basically characterized as visual structures.

\section{Latent Geometry and Modern Geometries}

What about the relationship between mathematics and the spatial frameworks I have illustrated? We can consider the spatial frameworks illustrated in the previous sections as local maps linked to people's activities who exploit them taking advantage of the pregnancy (for example landmarks) of special conceptual aspects. They are called spatial frameworks because they are perceived by human beings as forms of and helps for spatialization, constructed thanks to natural language, intuitions, and emotions, and consequently without the help of artificial and symbolic languages. For Thom, the creator of the well-known catastrophe theory we deal in these cases with the so-called somatic local maps. They are centered on the individual and function as forms of governing the external world together with the position of one's own body:

This conception of a flexible and individual space-time, which will cease to be a universal frame valid for all men, clearly conflicts head on with the basic postulate of all modern science that there exists a universal space-time valid and isomorphic for all. It is without doubt this essential difference that LéviBruhl had wished to signify in speaking of "pre-logical mentality" —unhappy

\footnotetext{
6 Brenner and Igamberdiev (2021), I have already quoted in the previous footnote, would further emphasize that the Cabala is intended to be read for its spiritual sense, and its diagrams, no more than those of the I Ching (the ancient Chinese Book of Changes), should not be taken literally.
} 
words, for logic has in principle, nothing to do with the representation of space (Thom 1980, p. 133).

In this light Thom redescribes the classical anthropological notion of participation, introduced by Lévy-Bruhl (1910), Lévy-Bruhl (1947), thanks to a new geometrical analysis. Participation refers the fact that two spatially separate living entities can be the same entity, and is related to the concept of "magic" and, Thom says, a process that cannot be considered as "pre-logic":

For example a sorcerer may be at one and the same time a man sleeping in a hut and a tiger hunting in the jungle some distance away [...] if the tiger is wounded by hunters in the jungle, then the man-sorcerer in his hut, will reveal a wound in the homologous place on his body. A belief of this kind justifies the statement that the man-sorcerer, and the tiger have their "local somatic maps" identified, and this in spite of the fact that these maps relate to beings separated by several kilometers (Thom 1980, p. 132).

Thom thinks that a magic action is linked to an "action at a distance" that can be mathematically rendered as a alteration of the standard topology of space-time. So to say "[...] the linking up between local maps which define the usual space will not be fixed, but could be modified at the pleasure, at the will of certain men (magicians or sorcerers), and this thanks to the use of specific procedures (magical rites, sacrifices, etc.)" (cit., p. 132) The topology of the space is no more the same for all, because the perceptual lived experiences of a watcher are themselves governed and modified by magical acts. We can also observe that the efficacious realization of somatic local maps and the alteration of the links between them is a kind of intrinsic-latent-geometric operation. I contend that a "latent geometry" is at play, as I will better explain below.

Our standard idea of geometry contemplates the independence, infinity, and fixedness of space that geometry itself reifies, which also "hosts" all the entities. At the same time geometry is always characterized by written (and diagrammatic, in the case of ordinary Euclidean geometry) counterparts: for us space "is" the Euclidean space. This kind of geometric space (and the same holds for the more complicated ones created by mathematical research, non-Euclidean, projective, multi-dimensional, etc.) appears to be, so to speak, "meaningless": the only meaning is the one that derives from the technical level of the written verbal, symbolic and artificial language, and from the possible diagrammatic dimensions, which for a long time established the total independence from the meanings carried by natural language of the everyday life.

Furthermore, more abstraction can be reached by removing the diagrammatic side, as Hilbert (1971) did thanks to the axiomatic formal systems. Modern physics finally consolidated the Euclidean geometric framework thanks to the establishment of the classical Newtonian ideas of space and time, which become the absolute and universal repositories of every experience. Since the affirmation of Euclidean geometry, non-esoteric cosmological and cosmogonic theories had to adopt the platform of objective space of geometry, from middle age to the current research in the area of scientific cosmology. The somatic local maps I have described above are always 
instead rich of meaningful pregnant features, which address to specific fields of everyday life domains related to ritual, sacred, cosmological and cosmogonic components, etc. When they generate space the local somatic maps at the same time reify shapes, routes, curves, and figures. We see these cases as referred to something geometrical: it is obvious to remember that many ethnic groups studied by anthropologists and other ancient people did not possess a geometry "textbook" appropriate to make them capable to classify their tools and operations as geometrical in their abstractness and independence.

As I have anticipated, the local somatic maps can be seen as the realization and actualization of a latent geometry, not yet endowed with a modern abstract and "principled" identification, that is symbolic and diagrammatic. By the way, we have to note that philosophers and geometers of the western mainstream tradition have always indicated that geometry, certainly characterized by a written and symbolic level, is also intertwined with intuitive, experiential, psychological, and corporeal aspects. We know that it is in the ancient Greece that geometry becomes an abstract business, written, symbolic, (informally) axiomatic, and originates the idea of a universal space, only representable thanks to a rigorous mathematical jargon, prior to the meaning effects of natural languages with their dense concepts, which derive from the everyday life.

Euclidean space becomes the norm for the human individuals, who indeed learn Euclidean geometry at school, and use it to model external surroundings and intuitive representations. Hence, these partial intuitive representations are always automatically coherent with the "global" geometric space of geometry. No surprise that Kant, in the transcendental Aesthetics, hypostatizes space, as a form of external senses and so "the condition of the possibility of appearances" (pure apprehension), and therefore the condition of possibility to identify objects and the a priori for any kind of nomination through the conceptual activity favored by language (empirical apprehension) (Magnani 2001b, chapters two and three).

Finally, our concept of implicit, latent geometrization can be subjected to a kind of metaphysical Platonic-Pythagorean interpretation: we can say it is not natural language and mind that create space but rather, that specific forms of a spatial scheme, of latent geometry, "enforce themselves" and are mediated by language and mental models.

Latent geometry exhibits another side of geometry, not standardly seen: bodily and local features, which we have encountered in the cases illustrated above and in symbolic tools, leave a vestigial trace in modern, scientific geometry, as Thom clearly notes:

It's striking to observe how most spaces, even in pure mathematics, are not homogeneous but are well and truly endowed with a base-point, an origin, the mathematical equivalent to a subject in a state of continual predation in the space. Even the typical picture of Cartesian axes $O x y[\ldots]$ conjures up irresistibly a mouth about to close on the typical point $p$, the prey (Thom 1972, p. 314).

A vestigial sign of a local somatic map is still present (cf. Fig. 6), as the trace-in this case against the Platonic-Pythagorean interpretation-of an inexorable character 


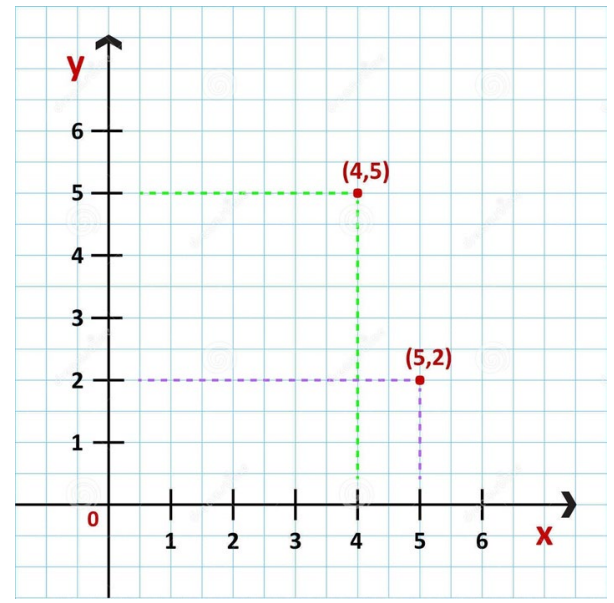

Fig. 6 Cartesian coordinate system in the plane vector illustration

of violent predation, ${ }^{7}$ together with a primordial "humanity" of geometry as a local "mold": "The same is found in pure mathematics, in algebraic topology, where the majority of spaces that are considered are built from a point-base, frequently linked to all the points of the space by continuous paths as in J. P. Serre's fibre-bundle theory" (Thom 1980, p. 137). I have said that this interpretation is against the Platonic-Pythagorean approach to spatiality because this tradition, which is certainly at the roots of western mathematical (geometrical) tradition, privileges - as it is wellknown-abstractions from all the concrete features of spatialization involving the biological and social aspects typical of human life.

The cognitive fruitfulness of geometries is great and great has been their role in shaping the world practically in all the disciplines and cultural traditions. From latent geometries to the modern ones we see a strong capability to make the word intelligible and practicable. In the end, also modern geometry (and mathematics) appears to generate - still adopting a Platonic-Pythagorean approach - a new more abstract mode of the old microcosm-macrocosm correspondence as a relationships between man's mathematical theories and mathematical structures that underlie the world. Indeed, in this perspective, Thom's Platonic-Pythagorean approach is extremely clear and explanatory, even if, philosophically, tremendously imperious:

I have reached the conviction that there are simulating structures of all natural external forces at the very heart of the genetic endowment of our species, at the unassailable depth of the Heraclitean logos of our soul, and that these structures are ready to go into action whenever necessary. The old idea of Man, the microcosm, mirroring World, the macrocosm, retains all its force (Thom 1972, pp. 324-325).

\footnotetext{
7 On the role of violence in its relationship to cognition and morality see Magnani (2011).
} 
Finally, a note specifically regarding the problem of the origin of geometry has to be added. Already the Pythagoreans, promoters of a new oral, esoteric, and militarily guarded mathematical knowledge, clearly and abstractly hypothesized not only that all things have a number, but that they are numbers. The origin of mathematics is "explained" by ontology. Especially, they prophetically considered geometry and arithmetic as "indivisible": this gave rise to a systematic protogeometry, consisting of a mixture of numbers and points (Magnani 2001b, chapter two, section 2.3). Here it could be of help for the reader to remember that a number is a mathematical entity exploited to count, measure, and mark. The foundamental examples are the natural numbers $1,2,3,4,[\ldots]$. Numbers can be rendered in a natural language with number words but their typicality consists in being expresses by symbols, called numerals: for instance, " 3 " is a numeral that refers to the number three. A point is turn standardly related to an entity of some set called a space. In Euclidean geometry, a point is a primitive concept upon which the geometry is developed: this means that a point cannot be defined in terms of previously defined entities, but just thanks to axioms. The geometric points do not possess length, area, volume or any other dimensional quality, and in Euclidean geometry always refer a unique location.

Alternatively, the problem of the origin of geometry is also treated by Neugebauer (1952) in the following way: he contends that what is called Pythagorean in cultural heritage of the ancient Greek tradition would have to be more suitably called Babylonian. Indeed in 1943 a cuneiform text concerning Pythagorean number triples was found and this hypothesis was confirmed. Others pointed out that religious books, like the Sulvasutras, exhibit ancient Indian works about the building of altars of the East that already presented the Pythagorean numbers. What is important to remember here is that, in the end, following Seidenberg $(1962,1978)$, geometry did not have a Greek genesis, but a strictly ritual one that derives from a more ancient East, a hypothesis that is related to a broader one that sees in rituals the entire origin of civilizations (Thibaut 1875). By the way, I have already illustrated in Sect. 2 above the general importance of rituals in building local somatic maps and semantic space.

In the last century, step after step the problem of individuating the origins of spatiality and of geometry becomes a complicated and pure philosophical conundrum. The main author who is related to this progress towards the maximum abstraction is Husserl, who proposes the famous and purely theoretical phenomenological approach, which indeed lacks any historical commitment. Geometry originates in a prescientific world, where experiential modes of taking measures (for example in surveying and in projects of buildings and of routes) can be regarded the foundation of the generation of pure geometrical idealities: "[...] the rough estimate of magnitudes is transformed into the measurement of magnitudes by counting the equal. [...] Measuring belongs to every culture" (Husserl 1978, p. 178). In mathematics, magnitude is the size of a mathematical entity, a property which describes whether the entity is bigger or littler than other similar entities. In this case Husserl uses the word "magnitude" in a more vague philosophical sense, as a kind of proto-practice of measuring that anyway is thought at the roots of idealities of Euclidean geometry.

In this perspective the approaches to the origins of space and of geometry of history and anthropology do not present anymore a great importance, even if Husserl discusses "magical" aspects and not the "ritual" ones: "For romantic spirits the 
mythical-magical elements of the historical and prehistorical aspects of mathematics may be particularly attractive; but to cling to this merely historically factual aspect of mathematics is precisely to lose oneself to a sort of romanticism and to overlook the genuine problem". This attitude is "mistaken in principle". The fundamental issue is the "internal-historical problem, the epistemological problem. Also, one's gaze obviously cannot then become free to recognize that facticities of any type, including those involved in the historicist objection, have a root in the essential structure of what is generally human, through which a teleological reason running throughout all historicity announces itself' (Husserl 1978, p. 178). ${ }^{8}$

However, both historical/anthropological and phenomenological accounts notably stress the importance - for producing spatiality and later on geometry-of manipulations of entities and of constructions (altars, and models like, for instance, "drawings" and sketches) in the external environment, linked to everyday practical needs, rituals, cosmological and cosmogonic stories, etc. Certainly this is related to human action and practices but also to the role of human body and of its motions and kinesthetic sensations.

\section{Conclusions}

I have treated the problem of the representations of space and time in the interplay between latent geometry, which is at work in elementary representations constructed thanks to natural language, and their rational re-creation, thanks to ancient Greek mathematics, which took advantage of the exploitation of an accurate diagrammatization of the research processes. In the case of latent geometry representations, bodies, and abstract and material artifacts such as homes, commerce, moving, routes, maps, rituals, and worldviews, are the main tools adopted to depict space and time and, possibly, cosmological and cosmogonic frameworks, contrarily to the case of explicit geometrical accounts, which create the first condition of possibility of the establishment of rational perspectives on cosmologies. I have contended that the approach to the role of diagrams, conceptual space and time, and latent geometry in the light of the development of Euclidean axiomatics represents a perfect philosophical and cognitive tool able to provide an explanation of the long process that arrives to the creation of concepts endowed with a "universal" value.

Acknowledgements Research for this article was supported by PRIN 2017 Research 20173YP4N3MIUR, Ministry of University and Research, Rome, Italy. Some parts of this article integrate various insights already sketched in Magnani (2001b, chapter one). For the instructive reports and precedent readings and correspondence that helped me to develop an analysis of the relationship between diagrams, conceptual space, and latent geometry I am indebted and grateful to all the colleagues who wrote sophisticated and precious books and articles concerning history and philosophy of geometry, and related issues in the areas of cognitive science and anthropology. These results kept the fundamental importance for western civilization of the intertwining between geometry and philosophy alive. Thanks also to the really helpful and constructive observations of the two reviewers who have allowed to improve the content of the article.

\footnotetext{
8 A detailed illustration of the Husserlian examination of the origins of geometry and of geometrical space is given in Magnani (2001b, chapter seven).
} 
Funding Open Access funding provided by Università degli Studi di Pavia.

Open Access This article is licensed under a Creative Commons Attribution 4.0 International License, which permits use, sharing, adaptation, distribution and reproduction in any medium or format, as long as you give appropriate credit to the original author(s) and the source, provide a link to the Creative Commons licence, and indicate if changes were made. The images or other third party material in this article are included in the article's Creative Commons licence, unless indicated otherwise in a credit line to the material. If material is not included in the article's Creative Commons licence and your intended use is not permitted by statutory regulation or exceeds the permitted use, you will need to obtain permission directly from the copyright holder. To view a copy of this licence, visit http://creativecommons.org/licen ses/by/4.0/.

\section{References}

Bergson H (1913) Time and free will: an essay on the immediate data of consciousness. Dover Publications, New York

Brenner JE, Igamberdiev A (2021) Philosophy in reality. A new book of changes. Springer, Cham

Centrone S (ed) (2017) Essays on Husserl's logic and philosophy of mathematics. Springer, Cham

Chevalier J (1969) Dictionnaire des symboles: mythes, reves, coutumes, gestes, formes, figures, couleurs, nombres, Sous la direction de Jean Chevalier; avec la collaboration de Alain Gheerbrant; dessins de Bernard Gandet. Laffont, Paris

Endicott K (1970) Malay magic. Clarendon Press, Oxford

Gärdenfors P (2000) Conceptual spaces: the geometry of thought. The MIT Press, Cambridge

Gladwin T (1970) East is a big bird. Navigation and logic on puluwat atoll. Harvard University Press, Cambridge

Griaule M, Dieterlen G (1954) The Dogon of the French Sudan. In: Forde D (ed) African Worlds. Oxford University Press, Oxford, pp 83-110

Hallpike C (1979) The foundations of primitive thought. Oxford University Press, Oxford

Hilbert D (1971) Foundations of geometry [1900]. Open Court, La Salle, IL

Husserl E (1970) The crisis of European sciences and transcendental phenomenology [1954]. George Allen \& Unwin and Humanities Press, London and New York, translated by. D. Carr

Husserl E (1978) The origin of geometry (1939). In: Derrida J (ed) Edmund Husserl's “The Origin of Geometry", Nicolas Hays, Stony Brooks, NY, pp 157-180, translated by D. Carr and originally published in Husserl (1970), pp 353-378

Hutchins E (1995) Cognition in the wild. The MIT Press, Cambridge, MA

Johnson-Laird PN (1993) Human and machine thinking. Erlbaum, Hillsdale, NJ

Jung CG (1972) On psychic energy. In: The Collected Works of CG Jung. Princeton University Press, Princeton, NJ, pp 3-66, translated by R. F. C. Hull, vol. 8, 2nd Edition

Lévy-Bruhl L (1910) Les fonctions mentales dans les sociétés inférieures. F. Alcan, Paris

Lévy-Bruhl L (1947) La mentalité primitive, 14th edn. Presses Universitaires de France, Paris

Magnani L (ed) (1978) Le geometrie non euclidee. Zanichelli, Bologna

Magnani L (2001a) Abduction, reason, and science. Processes of discovery and explanation. Kluwer Academic, New York

Magnani L (2001b) Philosophy and geometry. Theoretical and historical issues. Kluwer Academic Publisher, Dordrecht

Magnani L (2011) Understanding violence. The intertwining of morality, religion, and violence: a philosophical stance. Springer, Heidelberg

Magnani L (2018) Ritual artifacts as symbolic habits. Open Inf Sci 1(2):147-155

Neugebauer O (1952) The exact sciences in antiquity. Princeton University Press, Paris

Piaget J (1970) The child's conception of time. Basic Books, New York, 1 (1969), translation by A.1 Pomerans

Schmandt-Besserat D (1984) Before Writing, vol I. University of Texas Press, Austin, TX, From Counting to Cuneiform

Scholem G (1982) La Cabala. Edizioni Mediterranee, Rome

Seidenberg A (1962) The ritual origin of geometry. Arch Hist Exact Sci 1(5):488-527 
Seidenberg A (1978) The origin of mathematics. Arch Hist Exact Sci 18(4):301-342

Shin S, Lemon O, Mumma J (2018) Diagrams. In: Zalta EN (eds) The Stanford encyclopedia of philosophy, https://plato.stanford.edu/archives/win2018/entries/diagrams

Thibaut G (1875) On the Śulvasútras. J Asiatic Soc Bengal 44:227-275

Thom R (1972) Stabilité Structurelle et Morphogénèse. Essai d'une théorie générale des modèles. InterEditions, Paris, translated by D. H. Fowler, Structural stability and morphogenesis: an outline of a general theory of models, W. A. Benjamin, Reading, MA, 1975

Thom R (1980) Modèles mathématiques de la morphogenèse. Christian Bourgois, Paris, translated by W. M. Brookes and D. Rand, Mathematical models of morphogenesis, Ellis Horwood, Chichester, 1983

Torretti R (1978) Philosophy of geometry from Riemann to Poincaré. Reidel, Dordrecht

Tversky B (1981) Distortions in memory for maps. Cognit Psychol 13:407-433

Tversky B (1994) Spatial mental models from descriptions. J Am Soc Inf Sci 45:656-668

Tversky B (1995) Cognitive origins of graphic productions. In: Marchese F (ed) Understanding images. Finding meaning in digital imagery. Springer, Berlin, pp 29-53

Tversky B (2001) Spatial schemas in depiction. In: Gattis M (ed) Spatial schemas and abstract thought. The MIT Press, Cambridge, MA, pp 79-112

Tversky B, Agrawala M, Heiser J, Lee P, Hanrahan P, Phan D, Stolte C, Daniel MP (2006) Cognitive design principles: from cognitive models to computer models. In: Magnani L (ed) Model-based reasoning in science and engineering. College Publications, London

Zimmer H (1946) Myths and symbols in Indian art and civilization. In: Campbell J (eds). Pantheon Books, New York

Zolla E (1985) I mistici dell'occidente. Rizzoli, Milan

Publisher's Note Springer Nature remains neutral with regard to jurisdictional claims in published maps and institutional affiliations. 